\title{
Long term clinical outcomes associated with CMR quantified isolated left ventricular non-compaction in adults
}

\begin{abstract}
Background

Left ventricular non-compaction (LVNC) is a complex clinical condition with several diagnostic criteria but no diagnostic gold standard. We aimed to evaluate our thresholding technique in a group of patients with LVNC and assess the risk of major adverse cardiovascular and cerebrovascular events (MACCE).
\end{abstract}

\section{Methods}

We retrospectively analyzed cardiac magnetic resonance (CMR) scans of patients with Petersen criteria LVNC and quantified noncompacted myocardial mass. We assessed the association of noncompacted myocardial mass, CMR derived LV volumetric parameters and late gadolinium enhancement (LGE) to MACCE including cardiac death, cardiac transplantation, sustained ventricular tachycardia/ventricular fibrillation (VT/VF) and ischemic stroke. Patients with known genetic mutations and cardiovascular disease were excluded.

\section{Results}

98 patients with LVNC were included (55 males,56.7\%); 17(17.3\%) patients had impaired LV function and five (5.1\%) had LGE. Patients with impaired LV function had more end-systolic noncompacted mass $(61.9 \mathrm{~g} \pm 22.4$ vs. $38.1 \mathrm{~g} \pm 15.8, p<0.001)$ and larger end-systolic noncompacted to total myocardial mass $(44 \% \pm 9$ vs. $36 \% \pm 12, p=0.003)$. At 78 months followup [interquartile range(IQR) 66-90], MACCE occurred in 11(11.3\%) patients; nine(81.8\%) had impaired LV function and two(18.2\%) had LGE. Impaired LV function and LV LGE were predictors of MACCE $(\mathrm{HR}=35.6,95 \% \mathrm{Cl}=7.65-165.21, p<0.001$ and $\mathrm{HR}=16.2,95 \%$ $\mathrm{Cl}=4.54-57.84, \mathrm{p}<0.001)$ whereas noncompacted mass were not.

\section{Conclusion}

Noncompacted mass was not an independent predictor of major adverse events but in patients with impaired LV function and/or LV LGE, the risk of MACCE was high. These results highlight the importance of including LV volumetrics and scar in the assessment of patients with LV noncompaction.

\section{Keywords}

Left ventricular non-compaction

Cardiac magnetic resonance

Relative signal intensity

Myocardial mass 


\section{Introduction}

Left ventricular non-compaction (LVNC) is a heterogenous clinical condition characterized by a thickened endocardial layer with prominent trabeculae and a thinned, compacted epicardial layer [1]. Although LVNC has been categorized as an unclassified cardiomyopathy [2], establishing a diagnosis remains challenging with no universally accepted definition or "gold standard". Multiple 2-Dimensional echocardiography (2-D echo) and cardiac magnetic resonance(CMR) diagnostic criteria have been described but identifying patients that will develop complications such as LV systolic dysfunction, ventricular arrhythmias, ischemic stroke or cardiac death is difficult [[3], [4], [5], [6], [7]]. One commonly used CMR criteria proposed by Petersen and colleagues defines LVNC as an end-diastolic non-compacted to compacted myocardial ratio $>2.3$ in any long axis LV CMR image [7]. Growing evidence now shows that these criteria have poor correlation with clinical outcomes in patients with isolated, leading some to question whether non-compacted myocardium is a distinct pathological entity, a feature of other cardiovascular conditions or a phenotypical subtype [[8], [9], [10], [11]].

Using our previously described thresholding technique [12], we assessed the association of non-compacted myocardial mass, CMR derived LV volumetric parameters and LGE to major adverse cardiovascular and cerebrovascular events (MACCE) in patients with isolated LVNC.

\section{Methods}

\subsection{Patient selection}

This is a single centre study performed at a quaternary level referral facility with extensive CMR imaging experience and between January 2008 and December 2016, we conducted over 5000 CMR scans; 98 fulfilled the inclusion criteria. Scans were included for analysis if patients were referred with evidence of non-compaction on transthoracic echo, had one of the following clinical events (documented ventricular arrythmia, dyspnoea, ischemic stroke or transient ischemic event, syncope, undiagnosed palpitations, family history of LVNC or family history of sudden cardiac death) and fulfilled the Petersen criteria for LVNC [7]. Patients were excluded if they had a known genetic mutation, ischaemic heart disease, congenital heart disease, hypertrophic cardiomyopathy $(\mathrm{HCM})$, abnormal loading or infiltrative conditions. Children younger than 16 years of age are scanned at a different facility and were not included in the study. The study was conducted in accordance with institutional ethical research guidelines and approved by the Royal Prince Alfred Ethics and Governance Office No X17-0225 \& HREC/17/RPAH/339.

\subsection{Follow up, clinical data and outcome definitions}

Clinical data was retrieved retrospectively for all 98 patients by reviewing hospital medical records, contacting the referring cardiologist or by calling the patient or their next of kin between December 2018 and March 2019 for a total of 588 person-years. The primary endpoint of our study was a composite of cardiac death, cardiac transplantation, sustained ventricular tachycardia/ventricular fibrillation (VT/NF) and ischemic stroke. Cardiac death was defined as death attributable to congestive heart failure (i.e., death preceded by acute exacerbation or worsening of heart failure) or sudden death(i.e, unexpected, unwitnessed or witnessed death in the absence of other apparent causes). Sustained VT/VF were defined as $\geq 30$ s of hemodynamically stable VT or hemodynamically unstable VT/VF as documented by electrocardiogram, implanted cardiac monitor, implanted pacemaker or defibrillator. Serial assessment of LV systolic function was performed by the referring cardiologist using 2-D echo and available for $85(86.7 \%)$ of patients. Ischemic stroke was defined as an acute episode of focal cerebral or spinal dysfunction caused by infarction of the central nervous system 
tissue and diagnosed by computed tomography (CT) or MR imaging. Normal LV systolic function was defined as an LV ejection fraction (LV EF) $\geq 50 \%$. Normal indexed LV endsystolic and end-diastolic volumes were assessed by CMR and defined as less than $92 \mathrm{mls} / \mathrm{m}^{2}$ and $32 \mathrm{mls} / \mathrm{m}^{2}$ respectively [13].

\subsection{Cardiovascular MR protocol}

\subsubsection{Assessment of ventricular volumes, function and late gadolinium enhancement using cine MR Imaging}

CMR imaging was performed using a 1.5 T MR scanner (GE medical system). 4-chamber and short axis views covering the LV (9-12 contiguous slices) were acquired using retrospectively gated balanced steady-state free precession (bSSFP) cine MR images. Assessment of LV volumes was performed by manual segmentation of short-axis cine images with endocardial outline at end-systole and end-diastole (OsiriX software, version 3.6.1 32 bit). LV papillary muscleswere included as part of the compacted myocardial measurements. Simpson's rule was used to calculate end-systolic and end-diastolic volumes for the LV; LV EF was calculated from end-systolic and end-diastolic volumes. Data was analyzed independently by an experienced Level III SCMR accredited consultant in CMR (RP).

Scar imaging within the myocardium was performed with segmented phase-sensitive inversion recovery sequences (Image parameters: $T R=2 x R R$ interval; TE $=3.4 \mathrm{~ms}$; flip angle $=25$ degree; slice thickness $=10 \mathrm{~mm}$; matrix $=256 \times 144$; field- of-view $=300$ $380 \mathrm{~mm}$, acquired during a single breath-hold) 10 min post-administration of intravenous contrast $(0.2 \mathrm{mmol} / \mathrm{kg}$ of gadobutrol, Gadovist). A look-locker sequence was used to determine the null point of normal remote myocardium. Significant enhancement was defined as occurring at 2 standard deviations above the null point as previously described [12]. Scar burden was measured using OsiriX software and expressed as a percentage of the LV mass. The summated area of the delayed gadoliniumenhanced regions of the LV (usually identified within 8-10 short axis slices, in end diastole) was measured and multiplied by the slice thickness to give a volume of LV scar. The volume was multiplied by 1.05 to give a mass of the scar within the ventricle. This was expressed as a percentage of the total LV mass, which was determined by measuring difference in the total epicardial area compared to endocardial area of the entire LV during diastole, then multiplied by the slice thickness and 1.05 to convert volume to myocardial mass.

\subsubsection{Image analysis of compacted and non-compacted myocardium}

Our group has previously described a semi-automated technique based on the Otsu thresholding method to quantify non-compacted and compacted myocardial mass [12,14]. In brief, the lower limits of accepted signal intensities for non-compacted myocardium ranged from the lower signal intensity compacted myocardium ( $S I_{M Y O}$ ) at the septum in any given slice to the upper signal intensity derived by the following formula: $\mathrm{SI}_{\mathrm{MYO}}+\left[\mathrm{SI}_{\mathrm{BLOOD}}-\mathrm{SI}_{\mathrm{MYO}}\right]^{*} 0.5$. Papillary muscles that were morphologically normal were included as compacted mass. Eight $(8.3 \%)$ of the 97 scans could not be analyzed using this technique due to DICOM data formatting or artifact. The myocardial mass was described in terms of absolute non-compacted and compacted mass as well as non-compacted to total myocardial ratio.

\subsection{Reproducibility}

Intra-observer variability was assessed by comparing 2 independent sets of measurements made by the primary operator (GF). The co-efficient of variation was determined by dividing the difference between the measurements by the mean measurement for each variable measured. Agreement between the measurements was further analyzed using the Pearson 
correlation co-efficient. The co-efficient of variation was 3.95\% and the correlation co-efficient for consistency was 0.961 .

Inter-observer variability was described previously [12]; the co-efficient of variation was $3.2 \%$ and the intra-class co-efficient using two-way mixed models for consistency was 0.99 .

\subsection{Data and statistical analysis}

Data was expressed as median and interquartile range (IQR). All analyses were performed using Statistical Package for Social Sciences (SPSS) software, Version 24 (Chicago, Illinois). All statistical tests were 2-tailed and $p$-values $<0.05$ were considered statistically significant. Odds ratio and $95 \%$ confidence interval were calculated for comparisons of categorical variables between the two groups. Ventricular mass, volumes and quantified ratios were treated as continuous variables. Differences between the groups of continuous variables were analyzed using independent $t$-tests. Differences in categorical variables were assessed using Fisher's exact tests. Correlations between continuous variables were assessed using Pearson's correlation method and intra-observer variability was assessed using co-efficient of variation as well as by intra-class correlation coefficient. Cox regression modelling was used for the multivariable analyses and Kaplan-Meier analyses using log-rank testing was used to compare between group differences. The variables included were categorical age, gender, LV EF, LV end-systolic volume, LV end-diastolic volume, LV LGE, end-systolic non-compacted mass, end-systolic non-compacted mass to total myocardial mass, end-diastolic noncompacted mass and end-diastolic non-compacted mass to total myocardial mass.

\section{Results}

\subsection{Patient characteristics}

98 patients (56 males; $57.1 \%$ ) with a median age of 47 years [31-65] satisfied the inclusion criteria and included in the study; $21(21.4 \%)$ patients had exertional or paroxysmal nocturnal dyspnea, $18(18.3 \%)$ patients had undiagnosed palpitations, $17(17.3 \%)$ patients had a history of non-sustained ventricular tachycardia or more than 500 ventricular ectopic beats (VEBs) in a 24-h period, 14 (14.3\%) patients had a first degree family member diagnosed with LVNC, $14(14.3 \%)$ patients had syncope or pre-syncope, $7(7.1 \%)$ patients had a family history of sudden cardiac death and $7(7.1 \%)$ patients were being investigated for a possible transient ischemic accident; Table 1a. Of the patients, $17(17 / 98 ; 17.3 \%)$ had impaired LV systolic function (LV EF < 50\% on CMR) and five (5/98; 5.1\%) had LGE in compacted myocardium of the LV basal-septum in a mid-wall pattern consistent with myocardial scar; all five patients had impaired LV function. The mean percentage of scar to total myocardial mass (measured in ED) was $3.09 \%+/-1.69$. There were no significant demographic differences between patients with preserved and impaired LV function; Table $1 \mathrm{a}$.

Table 1a. Baseline patient characteristics for patients with preserved and impaired left ventricular systolic function.

\begin{tabular}{|c|c|c|c|}
\hline & $\begin{array}{l}\text { Preserved } \quad L V \\
\text { Function } N=81\end{array}$ & $\begin{array}{l}\text { Impaired } \\
\text { Function } N=17\end{array}$ & $\begin{array}{l}P \text { - } \\
\text { value }\end{array}$ \\
\hline $\begin{array}{l}\text { Age at Index Scan, median } \\
{[I Q R] \text {, years }}\end{array}$ & 43 IQR [31-55] & 52 IQR [32-65]; & 0.127 \\
\hline Sex (males), $n(\%)$ & $46(56.7 \%)$ & $12(70.5 \%)$ & 0.423 \\
\hline Weight, mean & $75 \mathrm{~kg}+/-18$ & $83 \mathrm{~kg}+/-22$ & 0.109 \\
\hline
\end{tabular}




\begin{tabular}{|c|c|c|c|}
\hline & $\begin{array}{l}\text { Preserved } \quad \text { LV } \\
\text { Function } N=81\end{array}$ & $\begin{array}{l}\text { Impaired } \\
\text { Function } N=17\end{array}$ & $\begin{array}{l}P \text { - } \\
\text { value }\end{array}$ \\
\hline Height, mean & $173 \mathrm{~cm}+/-11$ & $171 \mathrm{~cm} \mathrm{+/-} 9$ & 0.618 \\
\hline Body Surface Area, mean & $1.91 \mathrm{~m}^{2}+/-0.27$ & $1.95 m^{2}+/-0.31$ & 0.582 \\
\hline $\begin{array}{l}\text { Indications for Imaging } \\
\text { Evaluation }\end{array}$ & & & \\
\hline $\begin{array}{l}\text { Exertional or paroxysmal } \\
\text { nocturnal dyspnea, } n(\%)\end{array}$ & $17(20.9 \%)$ & $4(23.5 \%)$ & 0.755 \\
\hline $\begin{array}{l}\text { Undiagnosed } \\
\text { palpitations, } n(\%)\end{array}$ & $17(20.9 \%)$ & $2(11.8 \%)$ & 0.512 \\
\hline VT or VEBs (>500/24 h), $n(\%)$ & $11(13.5 \%)$ & $5(29.4 \%)$ & 0.145 \\
\hline $\begin{array}{l}\text { First degree family member } \\
\text { with LVNC, } n(\%)\end{array}$ & $10(12.3 \%)$ & $4(23.5 \%)$ & 0.257 \\
\hline $\begin{array}{l}\text { Syncope or } \quad \text { pre- } \\
\text { syncope, } n(\%)\end{array}$ & $13(16.1 \%)$ & $2(11.1 \%)$ & 1.000 \\
\hline $\begin{array}{l}\text { Family history of sudden } \\
\text { cardiac death, } n(\%)\end{array}$ & $7(8.6 \%)$ & $0(0 \%)$ & 0.349 \\
\hline $\begin{array}{l}\text { Possible Transient Ischemic } \\
\text { Accident } n(\%)\end{array}$ & $7(8.6 \%)$ & $0(0 \%)$ & 0.349 \\
\hline History of hypertension, $n(\%)$ & $7(8.6 \%)$ & $2(11.8 \%)$ & 0.652 \\
\hline
\end{tabular}

\subsection{Baseline CMR}

Comparing patients with preserved and impaired LV function, there were significant differences in indexed LV end-systolic volume $\left(30.7 \mathrm{mls} / \mathrm{m}^{2}+/-10.3 \mathrm{vs}\right.$. $69.0 \mathrm{mls} / \mathrm{m}^{2}+/-$ $23.1, p<0.001)$, end-diastolic volume $\left(81.2 \mathrm{mls} / \mathrm{m}^{2}+/-17.4\right.$ vs. $109.7 \mathrm{mls} / \mathrm{m}^{2}+/-26.3$, $\mathrm{p}<0.001)$ and LV EF $(62.9 \%+/-6.8$ vs. $38.1 \%+/-8.5, p<0.001)$. The end-diastolic noncompacted to compacted myocardial length ratio (Petersen criteria), septal and lateral LV wall thickness were similar between the two groups $(p=0.821$ and 0.332$) ;$ Table $1 \mathrm{~b}$.

Table 1b. Index cardiac magnetic resonance parameters for patients with preserved and impaired left ventricular systolic function.

\begin{tabular}{|c|c|c|c|}
\hline & $\begin{array}{l}\text { Preserved LV } \\
\text { Function } \\
\mathbf{N}=\mathbf{8 1}\end{array}$ & $\begin{array}{l}\text { Impaired LV } \\
\text { Function } \\
N=17\end{array}$ & $\begin{array}{l}P \text { - } \\
\text { value }\end{array}$ \\
\hline $\begin{array}{l}\text { Indexed LV end-systolic volume, } \\
\text { mean }\left(\mathrm{ml} / \mathrm{m}^{2}\right)\end{array}$ & $30.7 \pm 10.3$ & $69.0 \pm 23.1$ & $<0.001$ \\
\hline $\begin{array}{l}\text { Indexed LV end-diastolic volume, } \\
\text { mean }\left(\mathrm{ml} / \mathrm{m}^{2)}\right.\end{array}$ & $81.2 \pm 17.4$ & $109.7 \pm 26.3$ & $<0.001$ \\
\hline LV ejection fraction, mean & $62.9 \pm 6.9$ & $38.1 \pm 8.5$ & $<0.001$ \\
\hline $\begin{array}{l}\text { Non-compacted to compacted ratio } \\
\text { (Petersen Criteria), mean }\end{array}$ & $4.21 \pm 1.05$ & $3.94 \pm 0.995$ & 0.332 \\
\hline $\begin{array}{l}\text { Compacted LV wall thickness, mean } \\
(\mathrm{mm})\end{array}$ & $8.2 \pm 2.4$ & $8.5 \pm 1.9$ & 0.842 \\
\hline
\end{tabular}




\begin{tabular}{|l|l|l|l|}
\hline & $\begin{array}{l}\text { Preserved LV } \\
\text { Function } \\
\mathbf{N = 8 1}\end{array}$ & $\begin{array}{l}\text { Impaired LV } \\
\text { Function } \\
\mathbf{N = 1 7}\end{array}$ & $\begin{array}{l}\boldsymbol{P} \text { - } \\
\text { value }\end{array}$ \\
\hline Late Gadolinium Enhancement, $\boldsymbol{n}(\%)$ & 0 & $5(29.4 \%)$ & $<0.001$ \\
\hline
\end{tabular}

\subsection{Quantification of non-compacted myocardium}

Compared to patients with impaired LV function, those with preserved LV function had significantly less end-systolic (38.1 g +/- 15.8 vs. $61.9 \mathrm{~g}+/-22.4, p<0.001)$ and end-diastolic non-compacted mass (52.3 g $+/-17.3$ vs. $69.1 \mathrm{~g}+/-23.2, p=0.003)$. Patients with preserved LV function also had less end-systolic and end-diastolic compacted mass $(68.1 \mathrm{~g}+/-24.8 \mathrm{vs}$. $81.6 \mathrm{~g}+/-34.8, p=0.077$ and $58.4 \mathrm{~g}+/-21.2 \mathrm{vs} .83 .8 \mathrm{~g}+/-36.2, p<0.001)$. Comparing the two groups, the end-systolic non-compacted mass to total myocardial mass ratio was larger in patients with impaired LV function, but there was no difference in the end-diastolic ratio to total myocardial mass ratio $(36 \%+/-12$ vs. $44 \%+/-9$ and $48 \%+/-9$ vs. $46 \%+/-$ $11, p=0.004$ and 0.781 , respectively).

\subsection{Clinical follow up}

At a median follow-up period of 78 months [IQR 66-90], MACCE occurred in $11(11.3 \%)$ patients; nine $(81.8 \%)$ had reduced LV function and two $(18.2 \%)$ had LV LGE (Table 2$).$ Cardiac death occurred in three $(3 / 98 ; 3.1 \%)$ patients; three $(3 / 3 ; 100 \%)$ had impaired LV function and two $(2 / 3 ; 66.7 \%)$ had LV LGE. Cardiac transplantation occurred in two $(2 / 97$; $2.1 \%)$ patients; both had impaired LV function. Three $(3 / 98 ; 3.1 \%)$ patients had sustained VT/VF; two $(2 / 3 ; 66.7 \%)$ had impaired LV function. The patient with preserved LV function had a family history of sudden cardiac death without a diagnosis of LVNC, structural or arrhythmogenic heart disease. Four (4/98; 4.1\%) patients had an ischemic stroke; three (3/4; $75 \%)$ had impaired LV function and two $(2 / 4 ; 50 \%)$ had LV LGE. Only the patient with preserved LV function had a history of atrial fibrillation with several risk factors $\left(\mathrm{CHA}_{2} \mathrm{DS}_{2}-\right.$ VASc $=3$ ).

Table 2. Baseline and noncompaction characteristics for patients with and without major adverse cardiovascular and cerebrovascular events (MACCE) MACCE included cardiovascular death, cardiac transplantation, cardiac defibrillator, ventricular arrhythmias and ischemic stroke.

\begin{tabular}{|l|l|l|l|}
\hline & $\begin{array}{l}\text { MACCE } \\
\boldsymbol{N = 1 1}\end{array}$ & $\begin{array}{l}\text { No MACCE } \\
\boldsymbol{N = 8 7}\end{array}$ & $\begin{array}{l}\boldsymbol{P} \text { - } \\
\text { value }\end{array}$ \\
\hline Age, mean & $56.6 \pm 20.9$ & $48.6 \pm 16.2$ & 0.133 \\
\hline Sex, male, $\boldsymbol{n}(\%)$ & $12(75.0 \%)$ & $42(51.8 \%)$ & 0.542 \\
\hline LV ejection fraction, mean (\%) & $41.3 \pm 15.1$ & $61.35 \% \pm 8.9$ & $<0.001$ \\
\hline Indexed LV end-diastolic volume, $\mathbf{m l / \mathbf { m } ^ { 2 }}$ & $101.8 \pm 29.9$ & $83.6 \pm 19.2$ & 0.006 \\
\hline Indexed LV end-systolic volume, $\mathbf{m l / \mathbf { m } ^ { 2 }}$ & $63.1 \pm 28.9$ & $33.3 \pm 13.9$ & $<0.001$ \\
\hline Late Gadolinium Enhancement, $\boldsymbol{n}$ (\%) & $4(33.3 \%)$ & $1(1.2 \%)$ & $<0.001$ \\
\hline End-systolic non-compacted mass, mean (g) & $55.8 \pm 26.4$ & $39.9 \pm 17.2$ & $<0.001$ \\
\hline $\begin{array}{l}\text { End-systolic non-compacted } \\
\text { mass, mean (\%) }\end{array}$ & $41.5 \pm 10.1$ & $37.3 \pm 12.3$ & 0.262 \\
\hline End-diastolic non-compacted mass, mean (g) & $67.8 \pm 24.3$ & $53.4 \pm 17.3$ & 0.012 \\
\hline
\end{tabular}




\begin{tabular}{|c|c|c|c|}
\hline & $\begin{array}{l}\text { MACCE } \\
N=11\end{array}$ & $\begin{array}{l}\text { No MACCE } \\
N=87\end{array}$ & $\begin{array}{l}P \text { - } \\
\text { value }\end{array}$ \\
\hline $\begin{array}{l}\text { End-diastolic non-compacted mass/total } \\
\text { mass, mean (\%) }\end{array}$ & $48.8 \pm 12.7$ & $46.9 \pm 10.8$ & 0.583 \\
\hline
\end{tabular}

Serial assessment of LV function by 2-D echo was performed by the referring cardiologist and the most recent scan was available for $85(86.7 \%)$ patients at a median of 48 months [IQR 24 to 36 months] post index CMR scan; 83.9\% (68/81) of patients with preserved LV function and $100 \%(17 / 17)$ of patients with impaired LV function. All 68 (100\%) patients with preserved LV function maintained normal function including the two patients with an adverse event; median serial LV EF was $62 \%$ [IQR 58 to 67]. The 13 patients without serial imaging were called directly and reported no adverse clinical events or hospitalizations but were never rescanned. In the patients with impaired LV function, the median LV EF on serial imaging was $38 \%$ [IQR 32-46].

Using multivariate analysis, only impaired LV function, the presence of LGE and elevated LV end-systolic volume $\left(32 \mathrm{mls} / \mathrm{m}^{2}\right)$ were significant predictors of MACCE $(p<0.001, p=0.001$ and $p=0.018$ ). End-systolic and end-diastolic non-compacted mass were not predictors of $\operatorname{MACCE}(p=0.402$ and 0.321$)$.

Comparing patients with MACCE $(11 ; 11.2 \%)$ to patients without MACCE $(87,88.8 \%)$, LV EF, LV end-systolic volumes, LV end-diastolic volumes, non-compacted mass were significantly different between the two groups; Table 3. Cox univariate predictors of MACCE included impaired LV function and LV LGE $(\mathrm{HR}=35.6,95 \% \mathrm{Cl}=7.65-165.21, p<0.001$ and $\mathrm{HR}$ $=16.2,95 \% \mathrm{Cl} 4.54-57.84, \mathrm{p}<0.001$, respectively). End-systolic and end-diastolic noncompacted mass, both as continuous and binary parameters were not associated with MACCE $(H R=2.43,0.72-8.01, p=0.153$ and $H R=1.83,0.41-8.42, p=0.435)$. The MACCE-free Kaplan-Meier unadjusted curves according to indexed LV volumes, LV EF, LV scar and non-compacted mass showed that only patients with impaired LV function, LV LGE and enlarged LV end-systolic volume had a higher rate MACCE $(p<0.001,<0.001$ and 0.041); Fig. 1.

Table 3. Major adverse cardiovascular and cerebrovascular events (MACCE) in patients with preserved and impaired left ventricular function.

\begin{tabular}{|c|c|c|c|}
\hline & $\begin{array}{l}\text { Preserved } \quad \text { LV } \\
\text { Function } \\
N=81\end{array}$ & $\begin{array}{l}\text { Impaired } \\
\text { Function } \\
N=17\end{array}$ & $\begin{array}{l}P \text { - } \\
\text { value }\end{array}$ \\
\hline MACCE, $n(\%)$ & $2(2.5 \%)$ & $9(52.9 \%)$ & $<0.001$ \\
\hline Cardiovascular Death, $n(\%)$ & 0 & $3(17.6 \%)$ & 0.004 \\
\hline $\begin{array}{l}\text { Cardiac } \\
\text { Transplantation, } n(\%)\end{array}$ & 0 & $2(11.7 \%)$ & 0.026 \\
\hline $\begin{array}{l}\text { Ventricular } \\
\text { Arrhythmias, } n(\%)\end{array}$ & $1(1.2 \%)$ & $2^{\mathrm{a}}(11.7 \%)$ & 0.304 \\
\hline Ischemic Stroke, $n(\%)$ & $1(1.2 \%)$ & $3^{\mathrm{a}}(11.7 \%)$ & 0.069 \\
\hline
\end{tabular}

a

One patient had VT, cardiac transplantation and stroke and one patient had VT and stroke; only one MACCE was recorded per patient. 

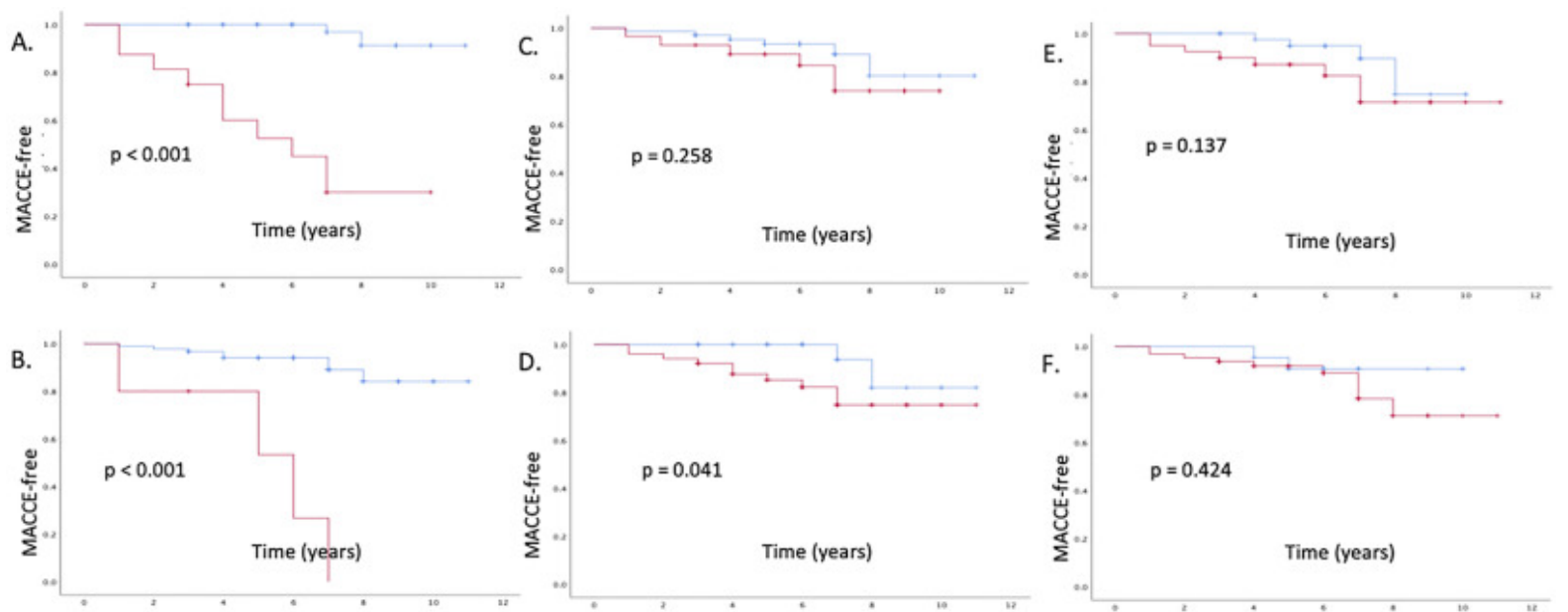

Fig. 1. Major adverse cardiovascular and cerebrovascular events (MACCE) - Free curves.

Kaplan-meier estimates of survival free of major cardiovascular and cerebrovascular events (MACCE) in patients who satisfy the Petersen criteria for left ventricular noncompaction according to (A) Left ventricular ejection fraction (LV EF) (B) Left ventricular late gadolinium enhancement (LGE) (C) Left ventricular end-diastolic volume (LVEDV) (D) Left ventricular end-systolic volume (LVESV) (E) End-diastolic noncompaction mass (EDNC) (F) End-systolic noncompaction mass.

\section{Discussion}

Despite numerous diagnostic criteria, distinguishing pathological from clinically benign hypertrabeculation remains challenging. In our cohort of patients fulfilling the Petersen criteria, hyper-trabeculation and non-compacted myocardial mass were not associated with adverse events. In fact, only patients with impaired LV function and LV LGE had high rates of complications while those with preserved LV function and no LGE had more benign clinical outcomes. These results highlight the need to expand the diagnostic criteria to include LV systolic dysfunction and scar in the assessment of patients with LV hyper-trabeculation.

The pathologic significance of isolated hyper-trabeculation within the left ventricle is controversial. Studies examining hyper-trabeculation in asymptomatic patients without heart disease, young athletes and pregnant women have found a high proportion of these individuals satisfy at least one of the current diagnostic criteria for LVNC [15,16]. From our cohort, we found that some patients with significant non-compacted mass ( $\geq 40 \%$ of total myocardial mass) were asymptomatic and had no adverse events. Overall, these results suggest that hyper-trabeculation does not always represent a pathological process but may rather be a phenotypic variant of normal myocardium or a physiological adaptation to a nonpathological stimulus in some cases. As such, some patients with hyper-trabeculation may not require aggressive medical management.

Given the lack of evidence linking hyper-trabeculation to pathological outcomes, the natural history of patients with pronounced non-compaction in the absence of any other cardiac abnormality is unknown. In fact, recent reports have demonstrated that only patients with impaired LV function, late gadolinium enhancement (LGE) and a history of ventricular arrhythmias, syncope or a family history of cardiomyopathy have a risk of adverse events [[17], [18], [19]]. One study found that in patients diagnosed with LVNC by both 2-D echo and CMR, cardiac events were only predicted by the presence of impaired LV function and LV LGE [17]. In another study, patients with non-ischemic dilated cardiomyopathy were assessed for LV non-compaction using two CMR criteria (Petersen and Jacquier) [18]. The authors found that cardiovascular outcomes were similar between those with hyper-trabeculation who 
satisfied the criteria for LVNC and those who did not, suggesting that hyper-trabeculation alone does not change the risk of adverse events. Finally, in keeping with our results, a recent meta-analysis of patients with LVNC found no cardiac events in those with preserved LV function and no LGE [20]. These results suggest that a more robust method for risk stratification amongst patients with LV hyper-trabeculation should include greater emphasis on LV function and presence or absence of LGE on CMR [21].

We suggest that patients with preserved LV function and no LV scar have follow up CMR imaging 3-5 years after the index scan. For those with reduced LV function and/or LV scar, we recommend close clinical surveillance. CMR in this setting could be considered when there is a significant change to the patient's clinical status and/or progression of LV dysfunction on 2-D echo. In the absence of these features CMR serial scans could performed 1-2 years after the index scan.

\section{Study limitations}

This study has some limitations. First, the number of patients with MACCE is small and while the data set was reviewed by two independent cardiologists, this single-centre retrospective analysis is subject to potential case selection bias. Second, eight CMR scans could not be evaluated with our thresholding technique due to DICOM data formatting or artifact. Third, we did not undertake formal genetic testing due to the low diagnostic yield and the considerable overlap in the genetic loci with other cardiomyopathies such as HCM but acknowledge that this may have enhanced the risk stratification of the cohort. Third, as serial assessment of LV function was limited to 2-D echo, we can only comment on LV function and not the development of myocardial scar over time.

\section{Conclusion}

Our study demonstrates that in patients that satisfy the Petersen LVNC criteria, the extent of noncompacted myocardium was not an independent predictor of MACCE but in those with impaired LV function and/or LV LGE, the risk of adverse events was high. In fact, patients with preserved LV function and no LGE had better clinical outcomes. These results highlight the need to expand current diagnostic criteria to include systolic dysfunction and scar in the assessment of patients with LV non-compaction for more optimal clinical risk stratification.

\section{Declaration of Competing Interest}

None.

\section{Acknowledgments}

Christopher Semsarian is the recipient of a National Health and Medical Research Council (NHMRC) Practitioner Fellowship (\#1154992).

\section{References}

T.K. Chin, J.K. Perloff, R.G. Williams, K. Jue, R. Mohrann

Isolated noncompaction of left ventricular myocardium

A Study Eight Cases. Circ., 82 (1990), pp. 507-512

P. Richardson, W. McKenna, M. Bristow, et al. 
Report of the 1995 World Health Organization/international society and Federation of Cardiology Task Force on the definition and classification of cardiomyopathies

Circulation, 93 (5) (1995), pp. 841-842

R. Jenni, E. Oechslin, J. Schneider, C. Attenhofer Jost, P.A. Kaufmann

Echocardiographic and pathoanatomical characteristics of isolated left ventricular non-compaction: a step towards classification as a distinct cardiomyopathy

Heart, 86 (6) (2001), pp. 666-671

C. Stollberger, J. Finsterer, G. Blazek

Left ventricular hypertrabeculation/noncompaction and association with additional cardiac abnormalities and neuromuscular disorders

Am. J. Cardiol., 90 (2002), pp. 899-902

A. Jacquier, F. Thuny, B. Jop, R. Giorgi, F. Cohen, et al.

Measurement of trabeculated left ventricular mass using cardiac magnetic resonance imaging in the diagnosis of left ventricular non-compaction

Eur. Heart J., 31 (9) (2010), pp. 1098-1104

R.B. Stacey, M.M. Andersen, M. St Clair, W.G. Hundley, V. Thohan

Comparison of systolic and diastolic criteria for isolated LV noncompaction in CMR

JACC Cardiovasc. Imaging, 6 (9) (2013), pp. 931-940

S.E. Petersen, J.B. Selvanayadam, F. Wiesmann, M. Robson, J. Francis, et al.

Left ventricular non-compaction: insights from cardiovascular magnetic resonance imaging

J. Am. Coll. Cardiol., 46 (1) (2005), pp. 101-105

S.B. Ross, K. Jones, B. Blanch, R. Puranik, K. McGeechan, et al.

A systematic review and meta-analysis of the prevalence of left ventricular noncompaction in adults

Eur. Heart J. (2019), pp. 1-11

A. Ivanov, D. Dabiesingh, G. Bhumireddy, G. Bhumireddy, A. Mohamed, et al. 
Prevalence and prognostic significance of left ventricular noncompaction in patients referred for cardiac magnetic resonance imaging

Circ.: Cardiovas. Imag. (2017), p. 10(9)

N. Kawel, M. Nacif, A. Arai, A. Gomes, G. Hundley, et al.

Trabeculated (non-compacted) and compact myocardium in adults: the multiethnic study of atherosclerosis

Circ.: Cardiovas. Imag., 5 (3) (2012), pp. 357-366

J. Weir-McCall, P. Yeap, C. Papagiorcopulo, K. Fitzgerald, S. Gandy, et al.

Left ventricular noncompaction: anatomical phenotype or distinct cardiomyopathy?

J. Am. Coll. Cardiol., 68 (20) (2016), pp. 2157-2165

P. Choudhary, C.J. Hsu, S. Grieve, C. Smillie, S. Singarayar, et al.

Improving the diagnosis of LV noncompaction with cardiac magnetic resonance imaging

Int. J. Cardiol., 181 (2015), pp. 430-436

N. Kawel-Boehm, A. Maceira, E. Valsangiacomo, J. Vogel-Claussen, E.Turkbey

Normal values for cardiovascular magnetic resonance in adults and children

J. Cardiovasc. Magn. Reson., 17 (2015), p. 29

N. Otsu

A threshold selection method from gray-level histograms

IEEE Trans. Syst. Man Cyber., 9 (1) (1979), pp. 62-64

S. Gati, N. Chandra, R. Bennett, M. Reed, G. Kervio, et al.

Increased left ventricular trabeculation in highly trained athletes: do we need more stringent criteria for the diagnosis of left ventricular non-compaction in athletes?

Heart, 99 (2013), pp. 401-408

S. Gati, M. Papadakis, N. Papamichael, A. Zaidi, N. Sheikh, et al.

Reversible de novo left ventricular trabeculations in pregnant women: implications for the diagnosis of left ventricular noncompaction in low-risk populations 
Circulation, 130 (2014), pp. 475-483

F. Zemrak, M.A. Ahlman, G. Captur, S. Mohiddin, N. Kawel-Boehm, et al.

The relationship of left ventricular trabeculation to ventricular function and structure over a 9.5 year follow-up

J. Am. Coll. Cardiol., 64 (19) (2014), pp. 1971-1980

D. Andreini, G. Pontone, J. Bogaert, A. Roghi, A. Barison, et al.

Long-term prognostic value of cardiac magnetic resonance in left ventricle noncompaction: a prospective multicenter study

J. Am. Coll. Cardiol., 68 (20) (2016), pp. 2166-2181

M. Amzulescu, M. Rousseau, S. Ahn, L. Boileau, C. de Meester de Ravenstein, et al.

Prognostic impact of Hypertrabeculation and non-compacted phenotype in dilated cardiomyopathy

J. Am. Coll. Cardiol., 8 (8) (2015), pp. 934-946

C. Grigoratos, A. Barison, A. Ivanov, D. Andreini, M. Amzulescu, et al.

Meta-analysis of the prognostic role of late gadolinium enhancement and global systolic impairment in left ventricular noncompaction

JACC Cardiovasc. Imaging, 12 (2019), pp. 2141-2151

N. Aung, F. Zemrak, S. Mohiddin, S. Petersen

LV noncompaction cardiomyopathy or just a lot of Trabeculations?

JACC Cardiovasc. Imaging, 10 (6) (2017), pp. 704-706 